\title{
The impact of tsetse fly control campaigns on African wildlife
}

\author{
Peter Matthiessen and Bob Douthwaite
}

From its earliest years, the Society's journal has carried reports on the tsetse problem in Africa. Between the 1920s and 1960s, attempts to eradicate the flies from many parts of the country resulted in the slaughter of 1.3 million game animals and extensive bush clearance, which permanently destroyed wildlife habitat. By the early 1970s, the use of insecticides had largely replaced these drastic techniques, but this, in its turn, with the environmental side-effects, caused much concern amongst wildlife conservationists. The authors review the history of tsetse control and discuss the new, safer methods that have been developed, as well as others still under trial. It is clear, however, that tsetse eradication will continue to be controversial. The development of safer and environmentally acceptable techniques does not solve a more fundamental problem - the wise use of Africa's land. Clearing the land of tsetse can open the path to its ruin by unsustainable pastoral encroachment. It is of interest that in April 1985, the EEC governments forced the EEC Commission to modify its forthcoming programme of tsetse fly eradication in four countries by insisting that environmentally harmful methods using DDT should not be employed. The Commission was also forced to include a three-year project on area development planning-land-use considerations were originally not included in its proposals.

It is an article of faith with certain sections of the conservation world that tsetse fly control campaigns are both damaging to wildlife and unnecessary. Even the media have been known to seize on this unlikely topic and seek to show 202 that African governments, with the assistance of aid donors, are busy poisoning both tsetse and irreplaceable fauna to make way for cattle and overgrazing. Like most scare stories, it has some factual basis, but we hope to demonstrate that the picture has been somewhat overdrawn. An historical survey of tsetse control, from its inception over 60 years ago to modem times, shows that environmentally harmful methods, which were often used in response to devastating sleeping sickness epidemics, have been largely replaced by relatively benign programmes. This does not, of course, imply that there is no room for improvement, as will be seen from several contemporary examples.

Tsetse flies Glossina spp. currently inhabit over 10 million square kilometres of tropical Africa in 34 countries (Figure 1). Their role in spreading 'nagana' in livestock and sleeping sickness in man has long been recognized. Traditionally, the risk of infection was minimized by avoiding flyinfested areas, but, with the establishment of colonial rule and the discovery that the causal agent was a parasitic protozoan Trypanosoma, a more active search for a solution to the problem began. The French and Belgian authorities, concerned mainly with human sleeping sickness, made their target the elimination of trypanosomes by medical methods, in the knowledge that, unless a vaccine could be developed, reinfection would be a constant threat. The British, on the other hand, opted for the final solution: to eliminate tsetse, and, in so doing, embarked upon a course that was to have major consequences for the environment.

Successful control of tsetse flies only became Oryx Vol 19 No 4 
possible when their unique life history and habitat requirements were properly understood. Females mate once only and retain the sperm internally. A single larva is hatched in utero at any one time, about eight offspring being produced in the mother's lifetime. The mature larva is deposited in a shady, humid site where it pupates underground, the time of adult emergence depending on temperature. The requirements of shade, humidity, temperature and availability of suitable hosts (mainly ungulates belonging to the Bovidae and Suidae) limit the distribution of tsetse to wooded areas between the Sahara and Kalahari deserts, and prevent their encroachment above certain altitudes. This knowledge makes it possible to predict the location and behaviour of tsetse populations, and is therefore vital for their control.

\section{Game destruction}

Robert Koch's discovery that Glossina palpalis favoured crocodiles for its bloodmeals led, in 1908 , to the first attempt to control tsetse by game eradication: a campaign in Tanganyika to eliminate crocodiles by collecting their eggs. David and Charles Livingstone had earlier proclaimed, in 1865 , that 'The destruction of all game by the advance of civilization is the only chance of getting rid of tsetse', and this view gained wide acceptance in the wake of the Great Rinderpest Epidemic. Rinderpest, a virus disease of ruminants, entered north-eastern Africa in 1889-90, and by 1896 had swept through to the Cape killing perhaps 90 per cent of the cattle, buffalo, eland, bushbuck, giraffe, bushpig and wart hog. In southern Africa, the disappearance of many game species led to local extinctions of tsetse in the Zambezi and Limpopo basins. Echoing the Livingstones, Bruce et al., (1913) stated, 'It is self-evident that wild animals should not be allowed to live in 'fly country' where they constitute a standing danger to the inhabitants and domestic animals ... Active measures should be taken for their early and complete blotting out'. This extreme view proved very influential, despite the rapid recovery of post-rinderpest game populations, an eventuality that boded ill for subsequent game 'extermination' campaigns. The attraction of killing two birds with one stone (i.e. destroying the parasite reservoir and starving the Tsetse fly control campaigns: effect on wildife

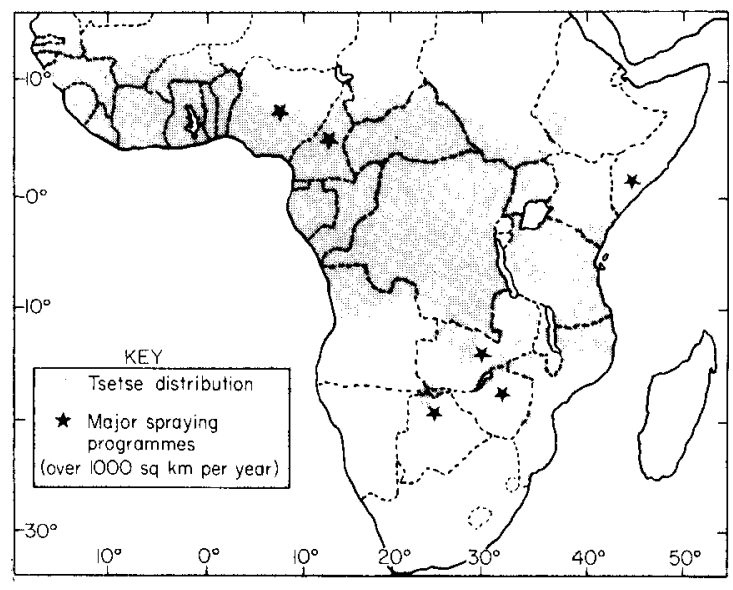

Figure 1. Distribution of tsetse flies.

tsetse of bloodmeals) was apparently still strong in the 1940 s when H. A. Crawshaw, the Veterinary Officer in the tsetse-infested Okavango Delta of Botswana, said that hunting is 'Nature's own method of tsetse fly control'.

Apart from a successful tsetse eradication campaign on the Portuguese colony of Principe Island (1911-14), which included the hunting down of wild pigs, the first control experiment to rely largely on hunting was started in Zimbabwe (then Southern Rhodesia) by R. W. Jack in 1919 (Chorley, 1958). By 1933 this had developed into a full-scale campaign of game slaughter, which continued until 1960, destroying an estimated 750,000 head and reclaiming approximately 26,000 sq km of infested land (Ford, 1971). Small numbers of animals in Zimbabwe (up to 2000 annually) are still shot in so-called game-free corridors. A similar scenario was enacted in Uganda (over 162,000 head shot in 22,000 sq km, 1944-70) (Jahnke, 1976), South Africa (over 175,000 head in $11,000 \mathrm{sq} \mathrm{km}$, 1929-46) (Du Toit, 1954), Botswana (over 63,000 head in 1800 sq km, 1939-67) (Davies, 1980b), Mozambique (over 60,000 head in 3000 sq km, 1949-58) (Andrade Silva and Marques da Silva, 1960), Tanzania (over 8000 head in $1500 \mathrm{sq} \mathrm{km}, 1945$-51) and Zambia (over 40,000 head, 1944-74) (Banage, 1979), as well as in smaller campaigns in other countries.

The slaughter of well over 1.3 million animals might have been justified if the measures had 
been effective, but, with the exception of Zimbabwe, this was not the case. Even here there were many setbacks because of game immigration from outside the control areas and failure to eradicate the smaller animals, such as wart hogs, which were hard to see in dense vegetation (Lovemore, 1961). In effect, most tsetse departments had merely been operating rather inefficient game-cropping techniques, and some populations actually increased (Child et al., 1970). Perhaps of greater significance was the needless destruction of many species that play only minor roles in the disease cycle. It was not until the late 1950s that bloodmeal analyses

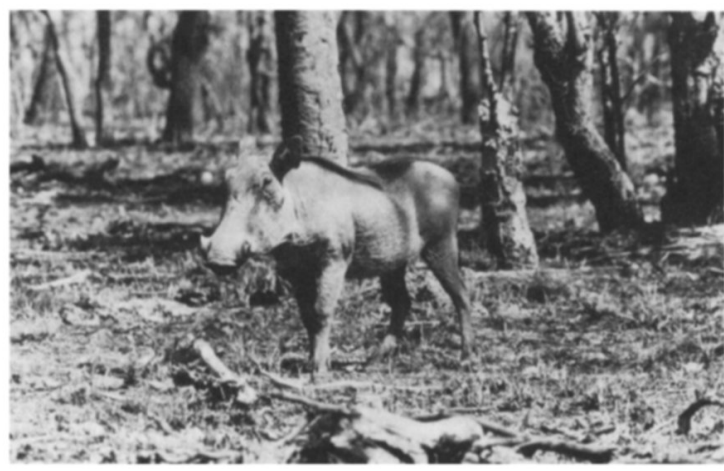

Figure 2. Wart hog: the most important host of savanna tsetse species (R.J. Douthwaite).

revealed a marked preference for just six hosts (wart hog, kudu, bushpig, bushbuck, buffalo and giraffe) among the important savanna and forest tsetse species. The Nagupande experiment in Zimbabwe (1962-67) proved that intensive hunting of only four of these ungulate species resulted in good tsetse control (Ford, 1971), but this vital information came too late. Before 1960 , over 36 species, including elephant, sable antelope, duiker, baboon and ostrich, were hunted unnecessarily (Potts and Jackson, 1952; Clarke, 1964; Wilson, 1975; Jahnke, 1976).

Despite this immense waste, there is no evidence to suggest that hunting caused permanent declines in any wild species, although this possibility was not scientifically studied. Game was certainly driven out from substantial areas, but other forms of game destruction (rinderpest control, safari hunting, poaching, crop protection, game cropping) often played a much more sig204 nificant role in the harrassment of Africa's faunal resources (Banage, 1979). Nevertheless, the public outcry against hunting as a means of tsetse control (Cockbill, 1967), together with convincing evidence for its inefficiency (Glover, 1965) and the advent of insecticides, largely ended the practice by the early 1970 s.

\section{Bush clearing}

Reinvasion of areas cleared of tsetse is almost assured unless they are settled by man. This is because both pastoralists and arable farmers tend to clear the bush, thereby making the area unsuitable for reinvading flies, which require a shady habitat. Bush clearance, however, was long used as an effective tsetse control technique in its own right. Mzila, one of the Ngoni chiefs of northern Mozambique, indulged in a massive bush clearance and game eradication scheme when resettling his people in the Msilizwe Valley in 1861 and, after Swynnerton (1925) had successfully followed his example in trials in Tanganyika, bush clearing became popular. It ranged from 'total' or 'ruthless' clearance of all trees and shrubs, through partial or selective clearing, which spared large trees but removed thicket and low-branching species, to so-called discriminative clearing in which woody vegetation was only removed from the areas of 'critical' habitat along drainage lines to which tsetse withdraw in the dry season (Ford et al., 1970) (Figure 3). Its main drawback, apart from the obvious destruction of wildlife habitat, was high cost combined with the need to prevent new growth by regular recutting. Political and economic troubles often led to reinfestation following failure to recut.

Habitat damage caused by bush clearing is difficult to quantify because the proportion of total clearing was not recorded in many cases. The countries carrying out major clearing programmes of some type included Uganda (more than $17,000 \mathrm{sq} \mathrm{km}, 1947-76$; still some reclearance), Tanzania (over 21,000 sq km, 1924 66), Nigeria (over 10,000 linear $\mathrm{km}$ of riverine forest, 1912-60), Botswana (over $2000 \mathrm{sq} \mathrm{km}$, 1944-67), and Ghana (over 2500 sq km, 192849), and most African countries have attempted the technique on a more limited scale. Even marginal areas cleared in this way were much Oryx Vol 19 No 4 


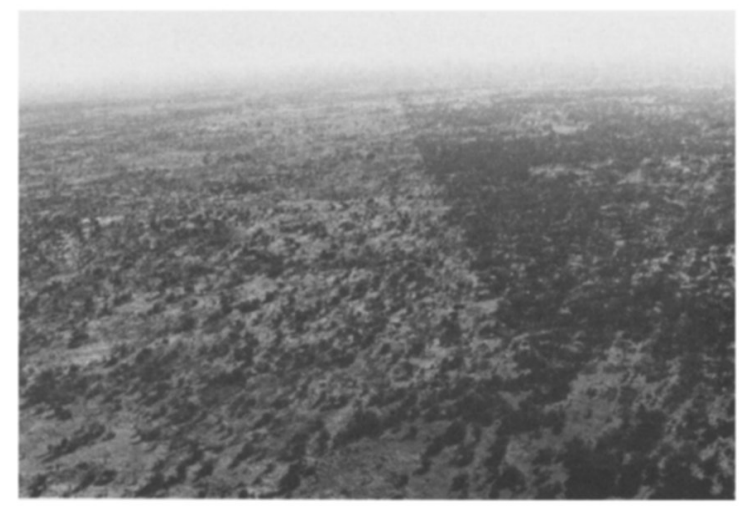

Figure 3. Regenerating woodland in a clear-felled area on the fringes of the Okavango Delta, Botswana.

more likely to be settled by man, so it can be assumed that a significant proportion of these campaigns led to permanent habitat destruction, with the inevitable loss of much of the wildlife.

\section{Insecticides}

Game destruction and bush clearing have now been largely superseded by the use of insecticides for tsetse control (Jordan, 1974; Mulligan, 1970; Allsopp, 1984), primarily for reasons of costeffectiveness. The persistent organochlorines, DDT and gamma-BHC (lindane), became available during World War II, and soon after hostilities ceased, J. J. Steyn started experimenting with DDT dust applied from war-surplus aircraft on an island in Lake Victoria. The first large-scale use of the new compounds was in Zululand by Du Toit (1954) where an attempt to eradicate the last South African focus of Glossina pallidipes by slaughtering 138,000 head of game in and around the Umfolozi, Hluhluwe and Mkuzi game reserves had been largely abandoned in 1946. The intention was to apply a persistent insecticide that would last until no more flies were left to emerge from subterranean pupae. A combination of ground-applied DDT dust and aerially applied BHC smoke subsequently managed to remove $G$. pallidipes from its last South African stronghold by 1954.

Residual spraying with BHC and DDT spread rapidly to all African countries with an active tsetse control department, and dieldrin was soon added to the insecticide armoury. As early as Tsetse fly control campaigns: effect on wildlife
1951, in Kenya, it was demonstrated by S. G. Wilson that DDT applied from the ground discriminately to tsetse resting sites is a very effective control method; however, indiscriminate aerial spraying of high doses (mainly dieldrin) nevertheless continues to the present in parts of Cameroon, Nigeria and Uganda. The discriminative ground-spraying technique has been developed to optimum efficiency in Zimbabwe where up to $8000 \mathrm{sq} \mathrm{km}$ per year are currently sprayed with as little as $200 \mathrm{~g}$ DDT/ha (Matthiessen, 1985). To date, over $300,000 \mathrm{sq} \mathrm{km}$ of Africa have been sprayed with DDT, dieldrin or gamma-BHC, of which an unknown proportion is now free of tsetse.

The environmental impact of these compounds received almost no attention up until the late 1960s, although Graham (1964) in Botswana and Wilson (1972) in Zambia noted that groundsprayed dieldrin killed over 69 species of birds, reptiles, small mammals and fish, and Du Toit (1954) recorded major kills of several non-target insect groups following the DDT and BHC spraying in the Umfolozi game reserve and elsewhere in Zululand. An intriguing postscript to Du Toit's observation appeared 30 years later (Downing and Russell, 1981) when it was shown that two families of flowering plants (Orchidaceae and Asclepidaceae) had almost vanished from the Umfolozi. Pollination of these plants is uniquely dependent on a few coevolved hymenopteran species, and it is suggested that the intense campaign of residual insecticide spraying killed the pollinators and prevented seed formation. Nevertheless, by 1970 it was still possible for the tsetse control 'bible' (The African Trypanosomiases, edited by H.W. Mulligan and W.H. Potts) to cover the environmental effects of insecticide spraying campaigns in a mere half page.

Even today, no comprehensive studies of the effects of DDT in tsetse areas have been published, although DDT residues from tsetse spraying in Zimbabwe are accumulating to high levels in some wildlife, and are probably responsible for significant eggshell thinning in the Lake Kariba fish eagle and other raptors (Matthiessen, 1985). By contrast, dieldrin has been more intensively investigated, and there is no doubt that it has serious and persistent effects on a large range of 


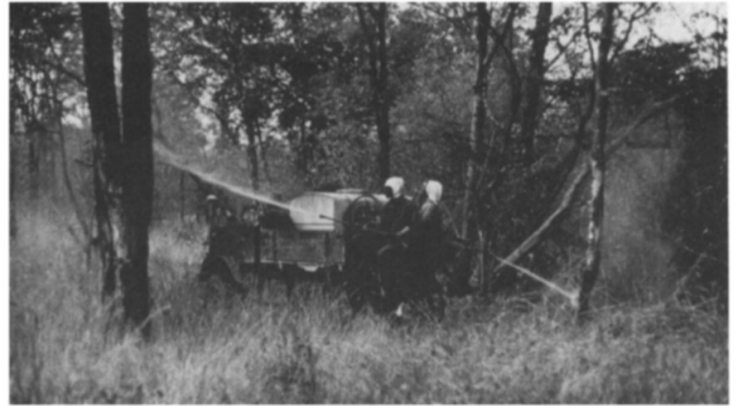

Figure 4. Treating tree trunks in Zambia with residual sprays of dieldrin or DDT in the late 1960s.

non-target organisms. Even small game animals can be killed by dieldrin (Wilson, 1972), although big game in Kenya was apparently unaffected (Allsopp, 1978), and it has been shown that the relative abundances of insects and insectivorous birds remain markedly depressed for at least a year after exposure (Müller et al., 1981; Koeman et al., 1971, 1978). A similar picture emerges when endosulfan, another organochlorine, is used at high residual doses (up to $1000 \mathrm{~g} / \mathrm{ha}$ ), except that in this case fish populations can also remain depressed for long periods (Koeman et al., 1978; Baldry et al., 1981; Everts et al., 1983).

Severe side-effects are not an inevitable byproduct of the insecticidal control of tsetse. Dose can be reduced by spraying sequentially, each spray timed to kill newly emerged flies before they deposit their larvae in the soil. The insecticide is dispersed in small droplets, usually by low-flying aircraft, to drift on the wind through tsetseinfested habitat. Four to six sprays are generally necessary over a period of 2-3 months but, under suitable conditions, dose rates as low as $6-18 \mathrm{~g} / \mathrm{ha}$ are effective. Early environmental studies of this revolutionary technique (Magadza, 1978; Cockbill, 1979; Takken et al., 1978) showed no serious effects on any animal group apart from tsetse, although a few fish died in shallow waters. More detailed studies by the Tropical Development and Research Institute in the Okavango Delta of Botswana (Douthwaite et al., 1981) confirmed this overall picture, but discovered sublethal changes in surviving fish, including a temporary inhibition of nest building in cichlid fish from sprayed areas. Recent additional work by us in Somalia has found evidence to suggest that honey-bees and little bee-eaters are 206 at risk when dose rates exceed $18 \mathrm{~g} /$ ha (Douthwaite, 1985), but the aerosol drift spraying technique is nevertheless the safest yet devised. To date, it has been used with varying degrees of success over approximately $90,000 \mathrm{sq} \mathrm{km}$, mainly in Botswana, Zambia, Nigeria, Zimbabwe and Somalia.

The application of aerosol drift sprays is still being perfected for use in hilly country, which currently requires ground-spraying with residual insecticides. Dieldrin is one of the products used for this purpose, but, given the major environmental problems associated with it, this seems to be unjustifiable. DDT ground-spraying therefore remains the insecticide of choice in hilly areas, but it would be prudent to discontinue its use as soon as alternatives exist. It is, in addition, clear that the aerial application of the known residual insecticides cannot be justified from the environmental point of view due to the indiscriminate nature of this method.

As for the future, several pesticide companies are now strongly pushing for the replacement of endosulfan with synthetic pyrethroid insecticides (especially alpha- and deltamethrin) for aerial drift spraying against tsetse. Deltamethrin has already been sprayed operationally in several countries (Uganda, 3220 sq km; Botswana, $>20,000$ sq km; Zimbabwe 2420 sq km; Cameroon), but at present it is not as successful as endosulfan. Several studies have shown that drift sprays of deltamethrin produce a very broadspectrum kill of tree-canopy and grassland insect species, as well as of aquatic crustacea (Smies et al., 1980; Takken et al., 1978; Baldry et al., 1981; Everts, 1979; Davies, 1980a), so it does not have either operational or environmental advantages over endosulfan. The efficacy of tsetse-attractive targets with insecticide-impregnated interceptory mesh screens, and of odour-baited, non-insecticidal tsetse control methods (sterile male release, odour-baited trapping etc.) is also on trial. The former have been used successfully on a small scale in Zimbabwe, Somalia and elsewhere, and are now being tested over $600 \mathrm{sq} \mathrm{km}$ in Zimbabwe. Targets and screens probably kill little apart from tsetse and are relatively cheap to produce and maintain, so it is hoped that they will replace dangerous residual spraying operations in the next few years. There are also moves afoot to Oryx Vol 19 No 4 
attempt the eradication of tsetse on an international scale in southern Africa, and, if these succeed, the need to respray will disappear as entire tsetse populations will be exterminated. The proposed programme implies that Zambia and Malawi will have to revise their policies of not allowing spraying operations in their national parks-decisions that are bound to be controversial.

\section{Land-use considerations}

Although tsetse control methods have become safer and more effective over the years, tsetse control campaigns themselves have become increasingly controversial. On the one hand, it is argued that enormous economic benefits would follow the reoccupation of land lost to pastoralism 80-90 years ago as a result of rinderpest, bush encroachment and the spread of tsetse. On the other, it is feared that tsetse eradication will be followed by the destruction of wildlife and its habitat, overgrazing, soil erosion and famine. Ormerod (1976) claimed, for instance, that tsetse control in West Africa has led to overgrazing by cattle belonging to nomadic herdsmen and is contributing to the Sahelian drought. As yet, there is no good evidence to suggest that the drought is due to man's mismanagement, but there is no doubt that overgrazing and other inappropriate land-use has occurred in tsetse-freed areas. The fact that this may eventually have happened anyway, with the livestock maintained on trypanocidal drugs, does not exonerate tsetse control as an agent of land degradation.

Many authorities, including FAO, now believe that large tsetse eradication campaigns should be preceded by detailed land-use planning so that, in theory at least, the occupation of virgin territory takes place in a controlled and optimum fashion (Jahnke, 1976; Jordan, 1979). Perhaps too little attention is being paid to the need also to monitor the changes as they occur. Generally, tsetse control departments do not consider the land-use implications of their work, but the National Tsetse and Trypanosomiasis Control Project of Somalia is an exception, considering some of the wider issues of tsetse eradication through an Environment Section. It remains to be seen, however, whether the manner and timing of eradication in Somalia will be influenced by the section's findTsetse fly control campaigns: effect on wildlife

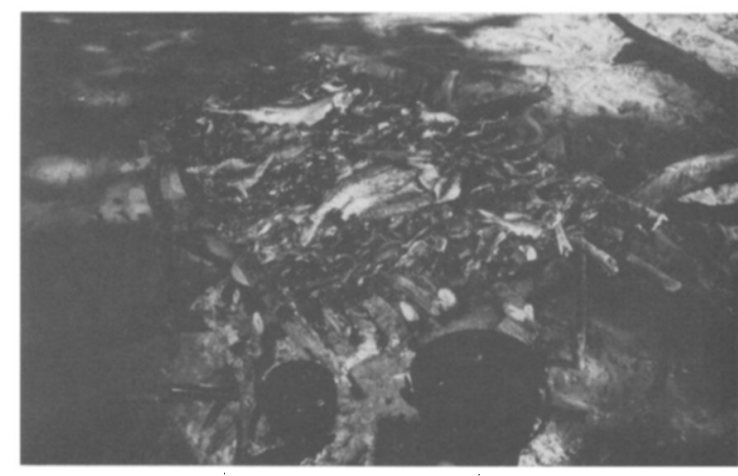

Figure 5. Fish killed by spraying with endosulfan are sometimes smoked and eaten - and are safe.

ings. In Botswana, livestock and wildlife interests compromised on their use of the Okavango Delta prior to tsetse eradication. A game- and stockproof fence was built across the Delta in 1983-84 to restrict cattle to the western and southern fringes, and game to the interior. Dramatic effects are now apparent, even from Space (Figure 6).

The eradication of tsetse from heavily settled areas affected by human sleeping sickness is clearly justified, as is the control of nagana where draught animals are important for arable farming and where livestock production is well established. Elsewhere, however, it could be argued that it would be better to intensify livestock productivity in tsetse-free areas than to allow, through tsetse control, the spread of livestock on to marginal land at the expense of wildlife. If African livestock owners were encouraged into the cash economy, husbandry would improve and might permit a much greater off-take from existing herds. The clearance of tsetse from marginal land in the Okavango Delta of Botswana, and in Zimbabwe and Zambia, is justified by claiming that adjacent areas of high agricultural potential are being protected from reinvasion. However, the benefits and costs of alternative solutions, and full costs of present actions, have not been comprehensively studied, with the risk that unsustainable pastoral encroachment may supplant the sustainable traditional practices of hunting, wildlife cropping, honey gathering, timber production, watershed protection and tourism.

The key to these problems is the degree of influence that governments are able to exert in the land-use (and family) planning process, and the 


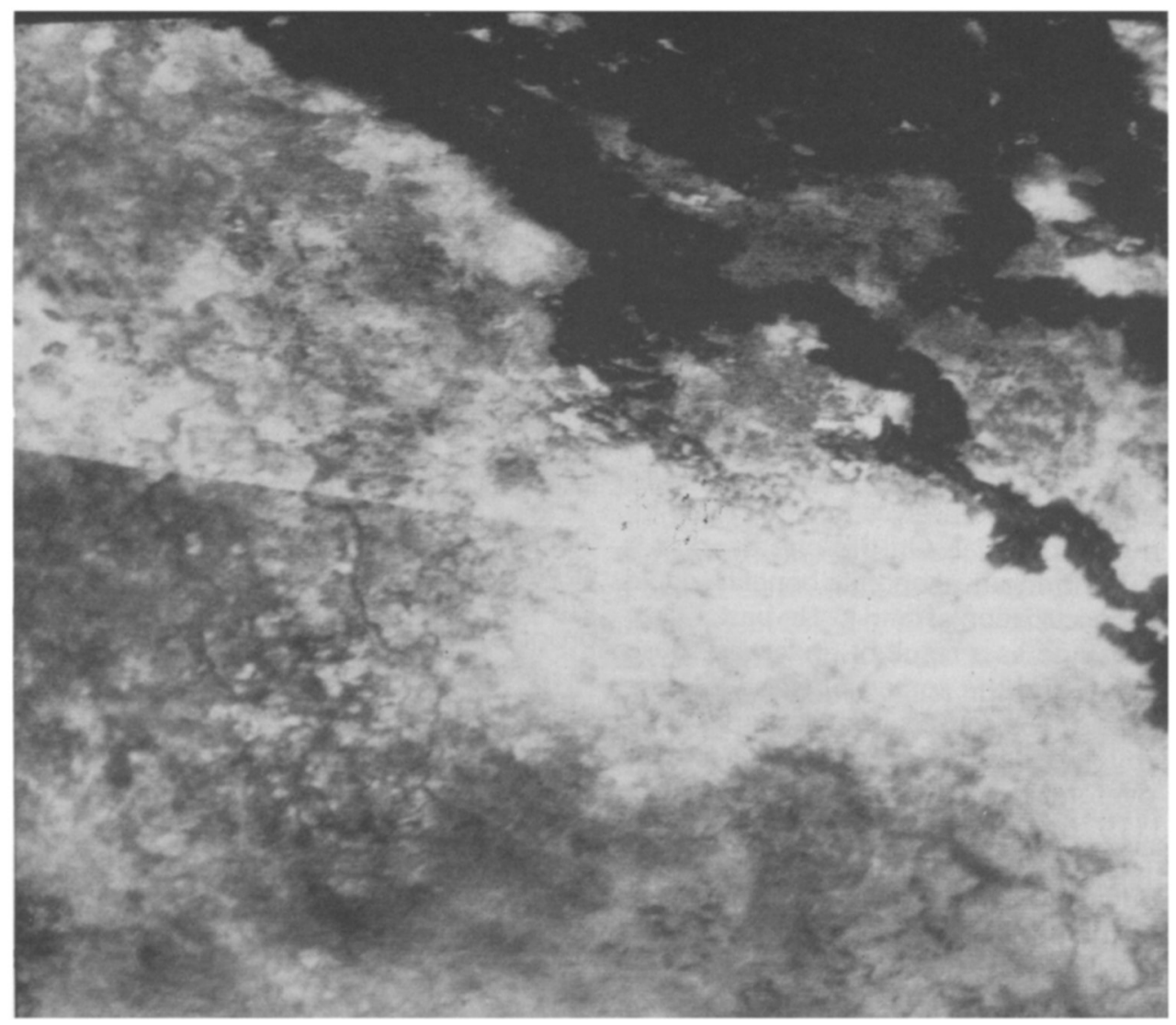

Figure 6. A Landsat photograph of the south-western corner of the Okavango Delta, Botswana, taken on $7 \mathrm{May}$ 1983. The line of the fence separating cattle and game is visible on the left; the paler areas are more heavily grazed, probably by cattle to the south and game to the north. The seasonal migration of zebra from the Delta to Lake Ngami may have been cut at this point.

extent to which they are able to intensify sustained use of the present tsetse-free lands rather than to encourage low-productivity encroachment on 'new' land. In the final analysis, the environmental effects of tsetse control can only be averted by political action.

\section{References}

Allsopp, R. 1978. The effects of dieldrin, sprayed by aerial application for tsetse control, on game animals. J. appl. Ecol. 15, 117-127.

Allsopp, R. 1984. Control of tsetse flies (Diptera: Glossinidae) using insecticides: a review and future prospects. Bull. ent. Res. 74, 1-23.

Andrade Silva, M.A. de and Marques da Silva, J. 1960. The tsetse fly (G. morsitans) eradication campaign in the Govuro district, Mozambique. Intemat. Scientific Committee for Trypanosomiasis Research. 8th meeting, Jos. Nigeria. pp. 253-264. Committee for Technical Co208 operation in Africa south of the Sahara. CCTA publ. no. 62 , London.

Baldry, D.A.T., Everts, J., Roman, B., Boon von Ochssee, G.A. and Laveissiere, C. 1981. The experimental application of insecticides from a helicopter for the control of riverine populations of Glossina tachinoides in West Africa. VII. The effects of two spray-applications of OMS-570 (endosulfan) and of OMS-1998 (decamethrin) on G. tachinoides and non-target organisms in Upper Volta. Trop. Pest Manag. 27, 83-110.

Banage, W.B. 1979. Wildlife conservation and its problems in Zambia. In Proceedings of the National Seminar on Environment and Development (Eds D. S. Johnson and W. Roder). Zambia Geographical Association Occasional Study No. 10, 77-110. Zambia Geographical Association, Lusaka.

Bruce, D., Harvey, D., Hamerton, A.E., Davey, J.B. and Bruce, Lady. 1913. The trypanosomes found in the blood of wild animals in the sleeping sickness area. Rep. sleep. Sick. Commn. R. Soc. No. 15, 16 pp.

Child, G., Smith, P. and von Richter, W. 1970. Tsetse control hunting as a measure of large mammal population trends in 
the Okavango Delta, Botswana. Mammalia, 34, 34-75.

Chorley, J.K. 1958. La lutte contre le mouche tse-tse en Rhodesie du Sud. Intermat. Scientific Committee for Trypanosomiasis Research, 6th meeting, Salisbury 1956, pp. $123-137$.

Clarke, J.E. 1964. Game elimination as a means of tsetse control with special reference to host preferences. Puku, 2 , 67-75.

Cockbill, G.F. 1967. The history and significance of trypanosomiasis problems in Rhodesia. Proc. Trans. Rhod. Sci. Assoc. 52, 7-15.

Cockbill, G.F. 1979. The effect of ultra-low-volume aerial applications of endosulfan applied against Glossina (Diptera: Glossinidae) on populations of non-target organisms in savanna woodland in Zimbabwe-Rhodesia. Bull. ent. Res. 69, 645-655.

Davies, J.E. 1980a. The Effects of Aerial Spraying with Decamethrin (NRDC 161) on Non-Target Tree-Canopy and Grassland Arthropods. Mimeo. Unpubl. report.

Davies, J.E. 1980b. The History of Tsetse Fly Control in Botswana, 165 pp. Tsetse Fly Control Department, Maun, Botswana.

Douthwaite, R.J. 1985. Environmental Aspects of Tsetse Fly Eradication in Somalia, 90 pp. Tropical Development and Research Institute, London.

Douthwaite, R.J., Fox, P.J., Matthiessen, P. and RussellSmith, A. 1981. The environmental impact of aerosols of endosulfan applied for tsetse fly control in the Okavango Delta, Botswana. Final Report of the Endosulfan Monitoring Project, 141 pp. London, Overseas Development Administration.

Downing, B.H. and Russell, G.E.G. 1981. Phytogeographic and biotic relationships of a savanna in southern Africa: analysis of an Angiosperm checklist from Acacia woodland in Zululand. J. S. Afr. Bot. 47, 721-742.

Du Toit, R. 1954. Trypanosomiasis in Zululand and the control of tsetse flies by chemical means. Onderstepoort $J$. vet. Res. 26, 317-387.

Everts, J.W. (ed.) 1979. Side Effects of Aerial Insecticide Applications Against Tsetse Flies Near Bouafle, Ivory Coast, 116 pp. Wageningen, Netherlands; Dept. of Toxicology, Agricultural University.

Everts, J.W., Frankenhuyzen, K. van, Roman, B., Cullen, J., Copplestone, J. and Koeman, J.H. 1983. Observations on side effects of endosulfan used to control tsetse in a settlement area in connection with a campaign against human sleeping sickness in Ivory Coast. Trop. Pest Manag. 29, 177-182.

Ford, J. 1971. The Role of the Trypanosomiases in African Ecology, 568 pp. Clarendon Press, Oxford.

Ford, J., Nash, T.A.M. and Welch, J.R. 1970. Control by clearing of vegetation. In The African Trypanosomiases (ed. H. W. Mulligan), 950 pp. George Allen \& Unwin, London.

Glover, P.E. 1965. A Review of Recent Knowledge on the Relationship Between the Tsetse Fly and its Vertebrate Hosts. IUCN Publications, New Series No. 6. Morges, Switzerland.

Graham, P. 1964. Destruction of birds and other wildlife by Dieldrex spraying against tsetse fly in Bechuanaland. Amoldia (Rhod.), 1, 1-4.

Jahnke, H.E. 1976. Tsetse Flies and Livestock Development in East Africa. 180 pp. Weltforum Verlag. Munich.

Tsetse fly control campaigns: effect on wildlife
Jordan, A.M. 1974. Recent developments in the ecology and methods of control of tsetse flies (Glossina spp.) (Dipt. Glossinidae): a review. Bull. ent. Res. 63, 361-399.

Jordan, A.M. 1979. Trypanosomiasis control and land use in Africa. Outlook in Agriculture, 10, 123-129.

Koeman, J.H., Den Boer, W.M.J., Feith, A.F., de longh, H.H., Spliethoff, P.C., Na'Isa, B.K. and Spielberger, U. 1978. Three years' observation on side effects of helicopter applications of insecticides used to exterminate Glossina species in Nigeria. Environ. Pollut. Ser. A, 15, 31-59.

Koeman, J.H., Rijksen, H.D., Smies, M., Na'Isa, B.K. and Maclennan, K.J.R. 1971. Faunal changes in a swamp habitat in Nigeria sprayed with insecticide to exterminate Glossina. Neth. J. Zool. 21, 434-463.

Lovemore, D.F. 1961. The effects of anti-tsetse shooting operations on the game populations as observed in the Sebungwe district, Southern Rhodesia. Symposium on Conservation of Natural Resources in Modern African States. IUCN Publications, New Series No. 1, 232-234. Morges, Switzerland.

Magadza, C.H.D. 1978. Field observations on the environmental effect of large-scale aerial applications of endosulfan in the eradication of Glossina morsitans centralis Westw. in the Western Province of Zambia in 1968. Rhod. J. agric. Res. 16, 211-220.

Matthiessen, P. 1985. Contamination of wildlife with DDT insecticide residues in relation to tsetse fly control operations in Zimbabwe. Environ. Pollut. Series B, 10(3).

Müller, P., Nagel, P. and Flacke, W. 1981. Ecological side effects of dieldrin application against tsetse flies in Adamaoua, Cameroon. Oecologia, 50, 187-194.

Mulligan, H.W. (ed.) 1970. The African Trypanosomiases, 950 pp. George Allen \& Unwin, London.

Ormerod, W.E. 1976. Ecological effect of control of African trypanosomiasis. Science, 191, 815-821.

Potts, W.H. and Jackson, C.H.N. 1952. The Shinyanga game destruction experiment. Bull. ent. Res. 43, 365-374.

Smies, M., Evers, R.H.J., Peijnenburg, F.H.M. and Koeman, J.H. 1980. Environmental aspects of field trials with pyrethroids to eradicate tsetse fly in Nigeria. Ecotoxicol. Environ. Safety, 4, 114-128.

Swynnerton, C.F.M. 1925. An experiment in the control of tsetse flies at Shinyanga, Tanganyika Territory. Bull. ent. Res. 15, 313-337.

Takken, W., Balk, F., Jansen, R.C. and Koeman, J.H. 1978. The experimental application of insecticides from a helicopter for the control of riverine populations of Glossina tachinoides in West Africa. V. Observations on side effects Pest Articles \& News Summaries, 24, 455-466.

Wilson, V.J. 1972. Observations on the effect of dieldrin on wildlife during tsetse fly Glossina morsitans control operations in eastern Zambia. Amoldia (Rhod.), 5, 1-12.

Wilson, V.J. 1975. Game and tsetse fly in eastern Zambia. Occ. Pap. natn. Mus. Rhod. B5, 339-404.

Peter Matthiessen, MAFF, Directorate of Fisheries Research, Fisheries Laboratory, Remembrance Avenue, Burnham-onCrouch, Essex CMO $8 \mathrm{HA}, \mathrm{UK}$.

Bob Douthwaite, Tropical Development and Research Institute, Overseas Development Administration, College House, Wrights Lane, London W8 5SJ, UK. 